\title{
Эволюция концепции устойчивости: мягкие меры для менеджмента рисков наводнений в Японии
}

\section{Микио Иииватари}

Токийский универсuтет, https://www.k.u-tokyo.ac.jp/

Резюме: Концепция устойчивости развивается, чтобы учесть различные изменения климата, социально-экономической ситуации, технологий и т.д. В этой статье анализируются области, влияющие на устойчивость, путем рассмотрения изменений политики управления рисками наводнений, особенно мягких мер, в Японии. Япония на протяжении всей своей истории справлялась со стихийными бедствиями и преуспела в сокращении ущерба от наводнений. В частности, государство инвестировало в инфраструктуру защиты от наводнений на уровне $1 \%$ национального дохода за последние полвека и, таким образом, смогло защитить крупные города от наводнений крупными реками. Хотя основные реки хорошо защищены, районы риска, прилегающие к небольшим рекам и холмистые местности, по-прежнему подвержены повторяющимся наводнениям. С 2000-х годов в стране расширяется использование таких мягких мер, как картографирование опасностей, раннее предупреждение и развитие эвакуации для защиты жизней людей. В статье рассматриваются развивающиеся процессы использования мягких мер путем пересмотра закона о борьбе с наводнениями. Было обнаружено, что концепция устойчивости в плане мягких мер развивается в соответствии с различными изменениями, такими как финансовые ограничения, сокращение инвестиций в инфраструктуру, старение населения, урбанизация, развитие технологий и климат. Основываясь на уроках развивающейся концепции устойчивости, автор рекомендует развивающимся странам внедрять мягкие меры с учетом различных изменений социально-экономических и природных условий и инвестировать в инфраструктуру.

Ключевые слова: защита от наводнений, Япония, инвестиции, инфраструктура, борьба с наводнениями, картографирование рисков. 


\section{Введение}

Концепция устойчивости развивается с учетом различных изменений климата, социально-экономических, технологических и других факторов. Каждая страна пытается повысить свою устойчивость к бедствиям в соответствии с местными условиями.

Япония имеет богатый исторический опыт управления рисками наводнений. Страна увеличила инвестиции в инфраструктуру защиты от наводнений и сумела уменьшить ущерб. Страна также не раз пересматривала закон о борьбе с наводнениями, чтобы отреагировать на возникающие потребности в мягких мерах, таких как планирование эвакуации, обмен информацией и картографирование опасностей.

Эта статья направлена на анализ областей, которые влияют на развитие устойчивости, путем обзора изменений политики управления рисками наводнений в Японии, особенно мягких мер. Кроме того, она предоставляет другим странам рекомендации по политике менеджмента рисков наводнений, основанные на собственных выводах и извлеченных уроках.

\section{Концепция устойчивости в Японии}

Управление Организации Объединенных Наций по снижению риска бедствий ${ }^{1}$ определяет устойчивость как «способность системы, сообщества или общества, подверженного опасностям, противостоять, абсорбировать, приспосабливаться, адаптироваться, трансформироваться и восстанавливаться после последствий опасности своевременно и эффективно, в том числе путем сохранения и восстановления его основных базовых структур и функций посредством управления рисками». Для повышения устойчивости необходимы координирующие институты, выявление и снижение рисков, готовность, финансовая и социальная защита и устойчивое восстановление. ${ }^{2}$ Сиодзаки и Като ${ }^{3}$ утверждают, что инженерная устойчивость имеет решающее значение для быстрого восстановления и что менеджмент рисков в городских системах можно осуществлять путем идентификации восстановимых воздействий.

Правительство Японии осуществляет инициативы по укреплению национальной устойчивости с целью создания безопасных и надежных национальных земель, регионов и экономического общества, обладающих силой

1 United Nations Office for Disaster Risk Reduction (UNDRR), "Terminology," https://www.undrr.org/terminology.

2 World Bank, Building Resilience: Integrating Climate and Disaster Risk into Development (Washington, DC: World Bank, 2013), https://openknowledge.worldbank.org/ handle/10986/16639.

3 Yuto Shiozaki and Takaaki Kato, "Definitions of Resilience and Vulnerability in Natural Disaster Research and Related Fields," Seisan Kenkyu 64, no. 4 (2012): 643-646, https://doi.org/10.11188/seisankenkyu.64.643. - на японском. 
и гибкостью, даже в случае каких-либо стихийных бедствий. ${ }^{4}$ Основные цели: (а) предотвратить человеческие жертвы, (б) избежать непоправимого ущерба важным функциям для поддержания административных, а также социальных и экономических систем, (в) уменьшить ущерб собственности граждан и общественных объектов и (г) добиться быстрого восстановления и реконструкции. Правительство планировало инвестировать 7 триллионов йен, около 64 миллиардов долларов США в развитие инфраструктуры для снижения риска бедствий с 2018 по 2020 годы. Правительство использует «устойчивость» как концепцию минимизации ущерба от кризиса, реализации быстрого восстановления и построения устойчивых и одинаково удобных для всех городов. Однако эксперты и исследователи используют термин “устойчивость» в разных значениях, и единой теории устойчивости к стихийным бедствиям не существует. ${ }^{5}$

В ходе исследований изучалось как различные секторы способствуют повышению устойчивости общества в Японии. Исаяма и Шоу ${ }^{6}$ утверждают, что сети сообществ, создаваемые в результате повседневной деятельности организациями социального обеспечения, медицинскими организациями и местными органами власти, способствуют укреплению устойчивости местных сообществ. Программа строительства общин, сконцентрированная вокруг школ, поддерживаемая министерством образования, восстанавливает устойчивость сообщества после Большого землетрясения и цунами в Восточной Японии в 2011 году. Школы становятся многофункциональными объектами, поддерживающими менеджмент ситуации при стихийных бедствиях, привлекая местные сообщества к управлению школами и участию в образовательные мероприятия. ${ }^{7}$ Социальная деятельность в местных сообществах, такая как фестивали, религиозные мероприятия и спортивные мероприятия, укрепляет отношения в сообществах, что ведет к повышению устойчивости сообществ. ${ }^{8}$ Однако имеющиеся литературные источники не

4 Cabinet Secretariat, "Building National Resilience - Creating a Strong and Flexible Country" (Tokyo: Cabinet Secretariat), https://www.cas.go.jp/jp/seisaku/kokudo_ kyoujinka/index_en.html.

5 Ryoga Ishihara, "Formation and Development of 'Disaster Resilience Theory' in Japan," in Depopulation, Deindustrialisation and Disasters, ed. Katsutaka Shiraishi and Nobutaka Matoba (Cham: Palgrave Macmillan, June 2019), 253-273, https://doi.org/10.10 07/978-3-030-14475-3_13.

6 Kenji Isayama and Rajib Shaw, "Building Disaster Resilient Community Through Healthcare Networking," in Community Practices for Disaster Risk Reduction in Japan, Disaster Risk Reduction: Methods, Approaches and Practices Series, ed. Rajib Shaw (Tokyo: Springer Japan, 2014), 91-120.

7 Shohei Matsuura and Rajib Shaw, "Concepts and Approaches of School Centered Disaster Resilient Communities," in Community Practices for Disaster Risk Reduction, 6389.

8 Miwa Abe and Rajib Shaw, "Community Resilience After Chuetsu Earthquake in 2004: Extinction or Relocation?" in Community Practices for Disaster Risk Reduction, 191208. 
охватывают эволюцию концепций устойчивости при управлении рисками наводнений в Японии.

\section{Исторический обзор уменьшения риска бедствий в Японии}

Япония боролась со стихийными бедствиями на протяжении всей своей долгой истории и создала культуру снижения риска стихийных бедствий. ${ }^{9}$ Император приказал построить насыпи вдоль реки Йодогава для защиты равнины Осаки еще в 4 веке. В средние века и в ранний современный период центральные администрации сегуната Бакуфу и Императора, а также Даймё, земельные феодалы строили сооружения для защиты стратегических районов замков и крупных городов от наводнений, используя местные знания и материалы. Кроме того, в борьбе с наводнениями участвовали местные жители, чтобы защитить себя и свое имущество. В 19 веке модернизированное правительство Мэйдзи ввело западную технологию защиты от наводнений из Нидерландов и других западных стран и начало строительство крупномасштабных сооружений для защиты сельскохозяйственных земель и городов от наводнений.

Японии удалось уменьшить ущерб от наводнений за счет инвестиций в инфраструктуру для защиты от наводнений. В 1940-х и 1950-х годах произошла серия наводнений, которые привели к значительным человеческим жертвам и экономическому ущербу. Ущерб, нанесенный экономике, достиг 10 \% национального дохода в 1947 году, а в 1959 году погибло более 5000 человек. Это связано с тем, что правительство не могло выделить достаточно средств на защиту от наводнений из-за военной экспансии и войн в 1930-х и 40-х годах. ${ }^{10}$ Государство инвестировало в инфраструктуру для защиты от наводнений на уровне примерно 1 \% национального дохода с 1940х по 1990-е годы. В середине 1990-х годов Цукахара и Качи ${ }^{11}$ оценили годовой доход от этих инвестиций в более чем 6 триллионов йен, или 55 миллиардов долларов США, что почти вдвое превышает объем инвестиций. Число погибших снизилось до менее 300 в 1990-х годах, а экономический ущерб снизился до менее 0,3 \% национального дохода (Фиг. 1).

9 Satoru Nishikawa, "From Yokohama Strategy to Hyogo Framework: Sharing the Japanese Experience of Disaster Risk Management," Asian Journal of Environment and Disaster Management 2, no. 3 (2010): 249-262, https://doi.org/10.3850/S179392401 1000459.

10 Mikio Ishiwatari and Kenichi Tsukahara, "Technical Note on the Estimation of Infrastructure Demand for Flood Control," in Bridging the Infrastructure Gap in Asia, ADBJICA Joint Side Event at the 50th Annual Meeting of the ADB Board of Governors" (Yokohama, 2017), https://www.jica.go.jp/jica-ri/publication/other/175nbg00000w ej43-att/5_JICA_Technical_Notes_DRR.pdf.

11 Kenichi Tsukahara and Noriyasu Kachi, "Using Data and Statistics to Explain Investment Effectiveness on Flood Protection," Journal of Disaster Research 11, no. 6 (2016): 1238-1243, https://doi.org/10.20965/jdr.2016.p1238. 
Япония может предотвращать почти все наводнения на крупных реках благодаря инвестициям в инфраструктуру в течение полвека. Однако страна не может полностью предотвратить наводнения в городских районах малыми и средними реками и притоками крупных рек, а также оползни и селевые потоки в горных районах.

С 2000-х годов правительство уменьшило бюджеты на защиту от наводнений из-за ограничений государственного бюджета, и при каждом наводнении возникали различные проблемы. Эвакуация людей, изолированных в районах затопления, запаздывала, несмотря на то, что государственные организации издавали предупреждения и приказы об эвакуации. Местные органы власти не могут своевременно выдавать приказы об эвакуации людей в зонах риска из-за их ограниченных способностей. Возможности для совместной работы в местных сообществах снижаются из-за урбанизации и старения населения. Уязвимые группы пожилых людей и инвалидов сталкиваются с трудностями при спасении от наводнения. В 2018 году более 200 человек погибли в западном регионе Японии из-за наводнения, вызванного проливным дождем беспрецедентного масштаба. Это был самый высокий показатель с 2004 года.

\section{Развитие концепции устойчивости и мягких мер}

История изменения закона о борьбе с наводнениями иллюстрирует эволюцию концепции устойчивости в применении к наводнениям в Японии. В дополнение к инфраструктурным мерам в стране разработаны мягкие меры,
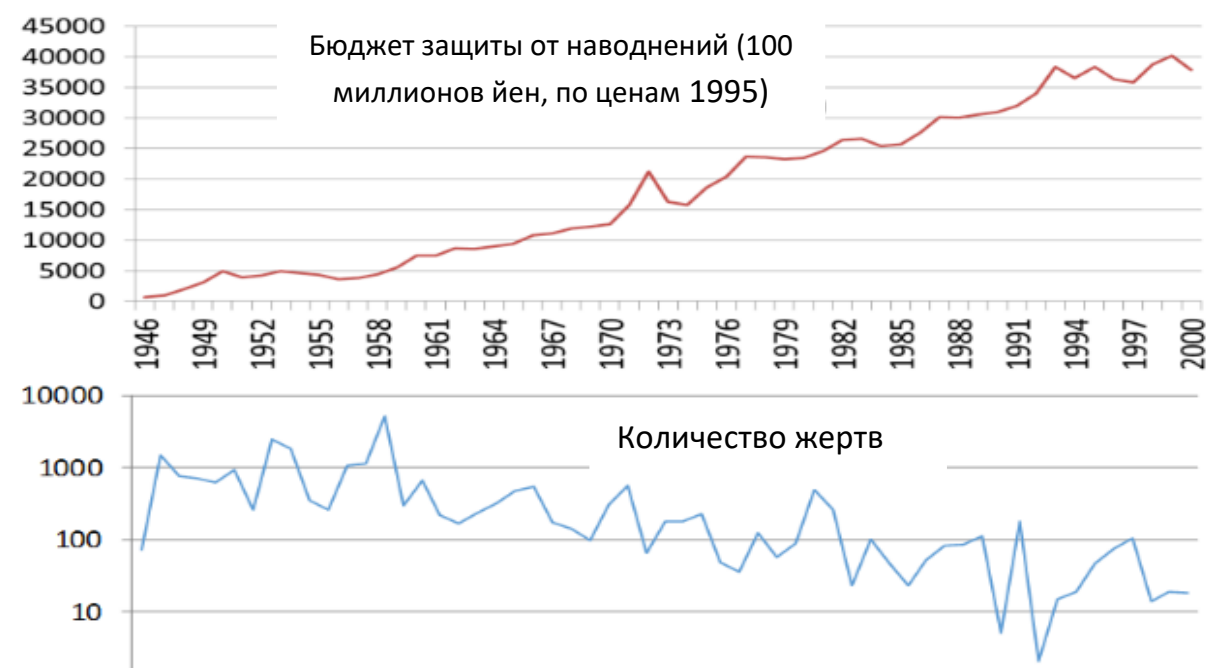

Фигура 1: Бюджеты программ защиты от наводнений и число погибших в Японии.

Источник: Микио Ишиватари, Японское управление по борьбе со стихийными бедствиями и стихийные бедствия в мире (Токио: Кашима Сюппанкай, 2016). - на японском. 
начиная с мероприятий по борьбе с наводнениями на местах, за которыми следует выпуск предупреждений, охватывающих малые и средние реки, картографирование опасностей и обмен информацией о рисках, содействие эвакуации с участием частного сектора, и защиты уязвимых групп, как показано в Таблице 1.

Таблица 1: История пересмотра Закона о борьбе с наводнениями.

\begin{tabular}{|c|c|c|}
\hline Год & Содержание редакции закона & Бедствия \\
\hline 1949 & $\begin{array}{l}\text { Закон был принят. } \\
\text { Борьба с наводнениями на месте }\end{array}$ & серия наводнений \\
\hline 1955 & $\begin{array}{l}\text { Прогнозирование наводнений и предупре- } \\
\text { ждение }\end{array}$ & \\
\hline 2001 & $\begin{array}{l}\text { Картирование рисков } \\
\text { Охват малых и средних рек }\end{array}$ & $\begin{array}{l}\text { Городское } \\
\text { наводнение в } \\
\text { Нагое }\end{array}$ \\
\hline 2005 & $\begin{array}{l}\text { Содействие эвакуации } \\
\text { Защита уязвимых групп }\end{array}$ & $\begin{array}{l}\text { проливные дожди } \\
\text { и тайфуны }\end{array}$ \\
\hline 2011 & $\begin{array}{l}\text { Включение бедствий, связанных с цунами } \\
\text { Защита участников борьбы с наводнениями } \\
\text { Поддержка национального правительства } \\
\text { при крупномасштабных бедствиях }\end{array}$ & $\begin{array}{l}\text { Большое земле- } \\
\text { трясение и цунами } \\
\text { в Восточной Япо- } \\
\text { нии }\end{array}$ \\
\hline 2013 & Привлечение частного сектора & $\begin{array}{l}\text { проливные дожди } \\
\text { и тайфуны }\end{array}$ \\
\hline 2015 & Реакция на мега-наводнения & \\
\hline 2017 & $\begin{array}{l}\text { Механизм координации между заинтересо- } \\
\text { ванными организациями } \\
\text { Планирование эвакуации и проведение уче- } \\
\text { ний для уязвимых групп }\end{array}$ & $\begin{array}{l}\text { Сильные дожди в } \\
\text { Канто и Тохоку }\end{array}$ \\
\hline
\end{tabular}

Закон о борьбе с наводнениями был принят в 1949 году. Поскольку в конце 1940-х и 1950-х годах почти каждый год происходила серия наводнений, уносящих жизни около 1000 человек, Японии необходимо было укрепить систему управления стихийными бедствиями, связанными с наводнениями. Закон направлен на защиту местных сообществ от наводнений и уменьшение ущерба от наводнений, что способствует поддержанию безопасности общества. Закон регулирует деятельность по борьбе с наводнениями на местах, возлагая основную ответственность на местные органы власти и создавая организации по борьбе с наводнениями.

В Японии существует многовековая традиция борьбы с наводнениями на уровне местных общин для защиты своих местных сообществ. Члены организаций по борьбе с наводнениями занимаются патрулированием берегов 
рек, ранним предупреждением, поддержкой эвакуации и укреплением берегов рек во время наводнений, а также складированием запасов материалов и проведением учений в обычное время. Поскольку борьба с наводнениями является неотьемлемой частью общественной деятельности по управлению водными ресурсами местных общин, ее происхождение неясно. Местные сообщества начали заниматься защитой от наводнений в то время, когда осваивались новые рисовые поля в средних веках. ${ }^{12}$

В 1955 году в закон были внесены поправки, касающиеся распространения информации о наводнениях. Государственные органы начали предупреждать население о наводнениях на крупных реках, находящихся в юрисдикции правительства страны, и предупреждать местные органы управления о необходимости борьбы с наводнениями. Предупреждение о борьбе с наводнением состоит из трех этапов: (а) подготовка, (б) мобилизация и (в) действия. Речные управления национального правительства оценивают конкретную стадию по уровням паводковых вод.

Закон не пересматривался почти полвека, но начиная с 2001 года начал подвергаться изменениям каждые несколько лет. Причина в том, что от государства ожидается реагирование на новые проблемы, такие как наводнения в городских районах, а также на малых и средних реках, и заблаговременное оповещение органов борьбы с наводнениями. Хотя государство реализовало инфраструктурные меры, страна не смогла дальше снизить число погибших.

В 2000 году от наводнения пострадал столичный район Нагоя. Эвакуация запоздала, подземные сооружения и метрополитен были затоплены. Было обнаружено, что государственные органы не предоставляли общественности достаточно информации о наводнениях и что обычные люди не осознавали риски наводнений.

В 2001 году, после наводнения в Нагое, закон о борьбе с наводнениями был пересмотрен, и власти префектур стали выпускать предупреждения о наводнениях на малых и средних реках. Национальные органы и органы префектур начали обмениваться информацией о рисках потенциальных районов затопления и глубине затопления с муниципальными властями. Закон требует от муниципальных властей подготовить эвакуацию, отдавая распоряжения об эвакуации и назначая убежища для эвакуации, а также предоставляя общественности карты опасностей и информационные карты. Муниципальные органы власти также должны предоставлять информацию о наводнениях для эвакуации из подземных сооружений.

В 2005 году страна несколько раз страдала от наводнений, вызванных тайфунами и проливными дождями. Было обнаружено несколько проблем. Около 60 \% погибших - пожилые люди. Прогнозы наводнений охватывают

12 Mikio Ishiwatari, "Government Roles in Community-Based Disaster Risk Reduction," in Community-Based Disaster Risk Reduction, ed. Rajib Shaw (Bingley: Emerald Group Publishing, 2012), 19-33, https://doi.org/10.1108/S2040-7262(2012)0000010008. 
только крупные реки и не включают информацию о площадях и глубинах затопления.

В 2006 году в закон были внесены поправки, предусматривающие предупреждение о рисках наводнений и предупреждения о наводнениях на малых и средних реках, а также включение в предупреждение о наводнениях территории и глубины затопления. Местные органы власти обязывались предоставлять карты опасностей и эвакуации, а также разработать маршруты транспорта к объектам для уязвимых групп пожилых людей и детей. Кроме того, муниципальные власти разрабатывают планы эвакуации подземных сооружений. Были созданы организации, помогающие борьбе с наводнениями, чтобы укрепить потенциал борьбы с наводнениями.

В 2011 году в результате Большого землетрясения и цунами в Восточной Японии погибло или пропало без вести более 20000 человек, а экономический ущерб составил 150 миллиардов долларов США. Более 200 сотрудников организаций по борьбе с наводнениями погибли во время мероприятий по ликвидации последствий стихийных бедствий. Закон был изменен, чтобы охватить катастрофы, связанные с цунами, и защитить жизни членов организаций по борьбе с наводнениями. Национальные правительственные организации могут привлекаться к борьбе с наводнениями во время особенно больших бедствий.

Возможности местных сообществ бороться с наводнениями ослабли изза урбанизации и изменений в промышленной структуре. Сельское население сократилось, и молодые поколения из сельских районов мигрировали в мегаполисы в поисках работы. Количество членов отрядов по борьбе с наводнениями уменьшилось, и они стареют. В 2013 году в закон были внесены поправки с целью вовлечения частного сектора в борьбу с наводнениями в целях поддержки местных сообществ. Кроме того, национальные правительственные организации обязуются поддерживать мероприятия по борьбе с наводнениями на местах. Частные компании должны разработать планы действий в чрезвычайных ситуациях, чтобы уменьшить ущерб, наносимый частным предприятиям и цепочкам поставок между частными компаниями.

В 2010-х годах по всей стране неоднократно происходили наводнения в масштабах, превышающих проектные уровни безопасности, обеспечиваемые структурными мерами. В 2015 году в закон были внесены поправки в связи с крупномасштабными наводнениями, которые невозможно предотвратить с помощью инфраструктурных мер. Органы власти обязаны составлять карты опасностей, которые показывают риски максимально возможных наводнений, приливов и городских наводнений, масштаб которых устанавливается на уровне интенсивности один раз в тысячу лет.

В 2015 и 2016 годах имелись случаи, когда пострадавшие люди не спаслись от наводнения и оказались изолированными в затопленных районах. В префектуре Иватэ девять пожилых людей не смогли спастись и все погибли в результате наводнения в доме для престарелых. 
В 2016 году в закон были внесены поправки, предусматривающие защиту уязвимых групп. Владельцы больниц, школ и учреждений для престарелых обязаны разработать планы эвакуации и проводить учения по эвакуации. Такие действия необходимо предпринять примерно 4000 учреждениям по всей стране. Для укрепления механизмов сотрудничества национальные власти и правительства префектур создают координационные комитеты, представляющие заинтересованные организации, такие как метеорологические службы, речные управления, местные органы власти, полиция, пожарные департаменты, силы самообороны и частные компании.

\section{Факторы, вызывающие эволюцию}

В этом разделе рассматриваются факторы, влияющие на устойчивость управления рисками наводнений. Япония смогла уменьшить экономический ущерб и потери в результате наводнений с 1940-х по 1990-е годы (Таблица 2). В основном это связано с тем, что государство инвестировало в инфраструктурные меры по защите от наводнений на крупных реках. Мягкие меры в основном касались борьбы с наводнениями на местах и обмена информацией о крупных реках.

Таблица 2: Разработка мягких мер, инвестиции и ущерб от наводнений.

\begin{tabular}{|c|c|c|c|c|c|c|c|c|}
\hline & $\begin{array}{l}1940 \\
-e\end{array}$ & $50-e$ & $60-e$ & $70-\mathrm{e}$ & $80-e$ & $90-e$ & $2000-e$ & $\overline{10-\mathrm{e}}$ \\
\hline $\begin{array}{l}\text { Борьба с } \\
\text { наводнениями }\end{array}$ & & & & & & & & \\
\hline $\begin{array}{l}\text { Прогнозирование и } \\
\text { предупреждение }\end{array}$ & & & & & & & & \\
\hline $\begin{array}{l}\text { Картирование } \\
\text { опасностей }\end{array}$ & & & & & & & & \\
\hline Эвакуация & & & & & & & & \\
\hline $\begin{array}{l}\text { Бюджет защиты от } \\
\text { наводнений, \% наци- } \\
\text { онального дохода }\end{array}$ & $\begin{array}{l}0.5- \\
2.0\end{array}$ & \multicolumn{5}{|c|}{$0.8-1.5$} & & \\
\hline Число погибших & \multicolumn{2}{|c|}{$<6,000$} & \multicolumn{3}{|c|}{$<1,000$} & \multicolumn{3}{|c|}{$<300$} \\
\hline $\begin{array}{l}\text { Экономический } \\
\text { ущерб, \% националь- } \\
\text { ного дохода }\end{array}$ & \multicolumn{2}{|c|}{$0.9-10.2$} & $<2.0$ & $<0.8$ & $<0.6$ & $<0.3$ & & \\
\hline
\end{tabular}

Число погибших снизилось до менее 300 в 1990-х годах, но не уменьшалось далее. Трудно полностью предотвратить наводнения, вызванные реками малых и средних размеров, а также ливневые паводки в горных районах. Например, есть еще 300000 районов, подверженных риску оползней.

Возможности местных общин бороться с наводнениями снизились из-за урбанизации и изменений в структуре промышленности. Правительству 
необходимо усилить мягкие меры. Национальные и местные органы власти начали составлять карты опасностей и распространять карты среди населения. Развитие технологии моделирования наводнений способствовало разработке карт опасностей. Правительство усилило меры по эвакуации, особенно для защиты уязвимых групп пожилых людей и инвалидов, а также уязвимых участков подземных сооружений.

\section{Заключение}

Опыт Японии показывает, что инвестиции в инфраструктуру эффективны для уменьшения ущерба от наводнений, но такие структурные меры могут в основном охватывать крупные реки. Защита всех зон риска, связанных с небольшими реками и оползнями, нереалистична, учитывая огромное количество зон риска в стране. В 2000-х годах Япония начала усиливать мягкие меры по дальнейшему снижению смертности при бедствиях.

Было установлено, что концепция устойчивости посредством мягких мер развивается в соответствии с различными изменениями, такими как финансовые ограничения, инвестиции в инфраструктуру, старение населения, урбанизация, развитие технологий и изменение климата. Охват мягких мер расширяется от борьбы с наводнениями на месте до обмена информацией, картирования опасностей, содействия эвакуации и защиты уязвимых групп. В то время, как в принятии мягких мер на протяжении последних столетий ведущую роль играли местные сообщества, в последнее время в мерах по борьбе с наводнениями и снижению рисков стали участвовать правительственные организации и частный сектор. Это связано с тем, что отношения между членами местных сообществ ослабли, а роль частного сектора в местных сообществах возросла.

\section{Некоторые соображения}

Из японского опыта можно извлечь некоторые уроки. Эти уроки полезны для развивающихся стран, все больше подверженных стихийным бедствиям, связанным с наводнениями. Развивающимся странам следует инвестировать в инфраструктуру защиты от наводнений в качестве рентабельной меры. Кроме того, развивающимся странам следует разработать мягкие меры с учетом различных изменений социально-экономических и природных условий. По мере роста экономики развивающиеся страны, как и Япония, подвергаются урбанизации, изменениям в структуре промышленности и миграции из сельских в городские районы.

\section{Отказ от ответственности}

Выраженные здесь взгляды являются исключительно взглядами автора и не отражают точку зрения Консорциума оборонных академий и институтов 
Устойчивость: мягкие меры для менеджмента рисков наводнений в Японии

изучения безопасности ПрМ, участвующих организаций или редакторов Консорциума.

\section{Благодарность}

Журнал Connections: The Quarterly Journal, Vol. 19, 2020 издается при поддержке правительства США.

\section{Об авторе}

Доктор Микио Ишиватари - приглашенный профессор Токийского университета и старший консультант по менеджменту проблем, связанных со стихийными бедствиями и водными ресурсами Японского агентства международного сотрудничества (JICA). Он дает советы и рекомендации по политике и деятельности JICA, а также проводит исследования и разработку проектов, администрирование и анализ в областях адаптации к изменению климата, управления ситуациями, связанными со стихийными бедствиями и управления водными ресурсами. Д-р Ишиватари также работал государственным инженером в Министерстве земли, инфраструктуры, транспорта и туризма Японии, специалистом по городскому развитию в Азиатском банке развития и старшим специалистом по управлению рисками стихийных бедствий во Всемирном банке. E-mail: Ishiwatari.mikio@jica.go.jp 